of the rest were young scientists who no longer see a future there.

Things are not much better at Bulgaria's universities, which will see an overall budget cut of $21 \%$ to $€ 170$ million this year compared with 2009. The large and research-intensive University of Sofia - which alone generates $30 \%$ of Bulgaria's scientific papers and patents - has to cope with a $23 \%$ cut in its 2009 budget to $€ 18$ million. "This is creating tensions between faculties, which are now fighting over tightened resources, and it's not pleasant," says Georgi Vayssilov, a chemist at Sofia. "Faculties such as chemistry and physics need more money for teaching, but our income is based on student number, so we are suffering a lot."

Vayssilov, like most of his colleagues, is also concerned about a law approved last month that allows universities to make their own rules for academic appointments and offers no guidelines or criteria. Consequently, one university might only appoint professors with strong publication lists, he says, whereas another might decide a couple of negligible publications would suffice, opening the door to cronyism.

Meanwhile, the country's granting agency, the National Science Fund, put out no general calls for proposals last year, and funding of some ongoing projects has been stopped or reduced. No new calls are expected this year.

\section{TOUGH BATTLE}

Until recently, scientists in Romania were in similar despair. In 2008, the country slipped into recession, and the unstable coalition government slashed the 2009 research budget by nearly $50 \%$. But the next coalition government, which came into power at the end of that year, took a different view: a huge budget hike this

\section{THE SPENDING GAP}

Research spending in both Romania and Bulgaria lags far behind that of other European nations. After a dip in 2009, Romania now looks set to boost investment in science.

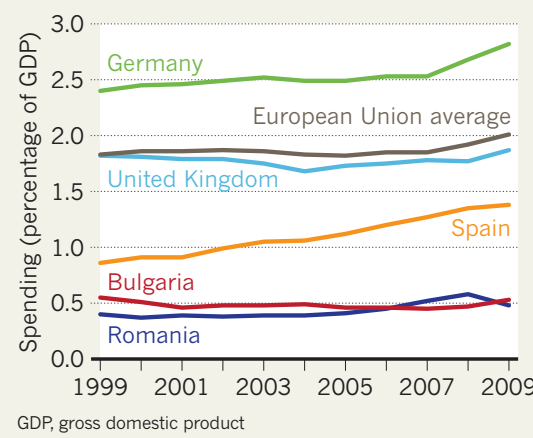

year comes close to returning research spending to 2008 levels. Unlike Bulgaria, Romania is continuing to bolster its research infrastructure, using EU structural funds for regional development.

Crucially, the country is introducing legislation to ensure the new funding is spent well. Research and education minister Daniel Funeriu, a former research chemist who spent most of his adult life abroad, championed an extensive and detailed education law that brings nearly all aspects of university governance, academic hiring practices, evaluation and guidelines for good scientific practice - complete with penalties for academic misdemeanours - into line with other European countries.

The law expressly forbids nepotistic $\rightarrow$ NATURE.COM

For a Q\&A with

go.nature.com/f8uyn2
Daniel Funeriu see: appointments, and also bars rectors from concurrently holding other positions of power that may pose a conflict of interest, such as being a member of parliament. "If these things didn't happen, we wouldn't have had to write them into the law," says Funeriu.

The draft law met huge resistance in parliament, in large part owing to the influence of several members who are also university rectors. The parliamentary education committee was particularly offended by a paragraph stating that the first round of quality assessment for universities must be done by foreign scientists. In the end, the government decided to force the bill through parliament with a vote of confidence, bypassing some of the parliamentary procedures that were blocking it. After being endorsed by the country's constitutional court on 4 January, the bill became law.

The government is now launching schemes to bring Romanian science into the international arena. In 2010 the country became a full member of CERN, the European particlephysics facility near Geneva, Switzerland, and also became a founding member of two major European facilities: the Extreme Light Infrastructure, which will develop the world's most intense lasers to study matter at high energies, and the particle accelerator Facility for Antiproton and Ion Research in Darmstadt, Germany. This year it is also planning to launch a twinning scheme, which would allow scientists working abroad to set up a parallel lab in Romania. That way they could contribute to science in Romania without having to risk leaving a good job elsewhere; and local staff would benefit from greater contact with international science.

Funeriu says that it has been a hard fight to get to this stage, but he is now optimistic for the future of Romanian science. "Winning this battle was tougher than any chemical synthesis I have done," he says.

\title{
Space scope finds scorched super-Earth
}

\section{Kepler's latest discovery is step closer to a true Earth analogue.}

\section{BY ADAM MANN}

$\mathrm{K}$ epler, the space telescope considered most likely over the next few years to identify an Earth-like planet orbiting another star, has struck solid ground, mission scientists say.

Most of the hundreds of extrasolar planets discovered to date - including the eight previously reported by Kepler - are at least as large as Neptune and are mainly gas giants. But astronomers hope that the mission will eventually yield a trove of terrestrial planets, including some orbiting their stars at a distance that would allow their surfaces to host liquid water, and possibly life.

Now the team is a step nearer to that goal. It has found a Sun-like star 173 parsecs away relatively close by galactic standards - harbouring a planet that is just $40 \%$ larger than Earth, although it is uninhabitably hot. Supporting measurements of the planet's mass, gathered at the Keck Observatory on Mauna Kea, Hawaii, suggest that the planet's density is 1.6 times that of Earth, implying a rocky composition. Although other telescopes have already spotted a handful of similar 'super-Earths', the first confirmed rocky planet to fall within Kepler's sights is an encouraging sign for the mission.

"It's a milestone," says co-investigator Natalie Batalha, an astronomer at San José State University in California, who unveiled news of the discovery during a talk on 10 January at the American Astronomical Society's annual meeting in Seattle, Washington.

Launched by NASA in 2009, Kepler's strategy is to point at a patch of sky in the plane of the Milky Way, where it can continuously monitor more than 100,000 stars, and to look for slight, periodic changes in their luminosity. Such dips in brightness often indicate the presence of planets repeatedly crossing in 
front of the stars they orbit. So far, after barely a year of observations, Kepler is limited to detecting short-period planets, those close to their stars.

The new-found planet orbits its star - designated Kepler 10 - every 20 hours, at a distance of 2.5 million kilometres. This is less than $2 \%$ of the distance separating Earth and the Sun, ensuring that the planet is more 'terra lava' than terra firma, with a surface temperature of $1,800{ }^{\circ} \mathrm{C}$, hot enough to melt silicate rock.

Astronomers at Keck were able to monitor how the planet tugs on the star, giving them its mass. Meanwhile, because the star is nearer than most of the stars in Kepler's search field, the Kepler

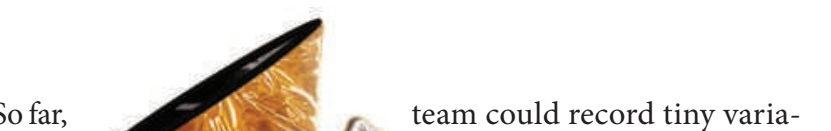
tions in the star's luminosity due to sound waves rippling through its interior. The timing of these acoustic oscillations provided detailed information about the star's dimensions, much as the sound of a string on a bow reveals whether the instrument being played is a violin or a cello.

"Everything we measure about the planet is relative to the parent star," says Batalha. Armed with a precise figure for the star's diameter, she and her colleagues were able to nail down the planet's dimensions with similar precision.

The planet's close orbit is similar to that of another rocky exoplanet, CoRoT-7b, discovered in 2009, says Greg Laughlin, an astronomer at

the University of California, Santa Cruz, who 䍃 was not involved in the work. He says the result $\frac{\pi}{z}$ shows how far astronomers' techniques for

The first confirmed rocky planet to fall within Kepler's sights is an encouraging sign for the mission.

Laughlin. Their existence suggests that cooler smaller worlds await discovery as Kepler's monitoring time increases and it can identify planets in longer, more distant orbits, he adds.

In February, the Kepler mission is expected to release data on 400 additional planetary candidates. The team is excited, says Batalha, because it hopes that Kepler's growing number of detections will offer the first concrete estimates of the frequency of extrasolar planets rocky and otherwise. "So far, it's been a deluge," says Batalha. "And we look forward to finding a lot more planets." -

\section{Drought-tolerant maize gets US debut}

\section{Seed companies race to tap multibillion-dollar market.}

\section{BY JEFF TOLLEFSON}

$\mathrm{W}$ hen the planting season arrives later this year, farmers in the United States will have a new way to safeguard their crops from drought. Last week, DuPont subsidiary Pioneer Hi-Bred International, headquartered in Johnston, Iowa, announced plans to release a series of hybrid maize (corn) strains that can flourish with less water. The seeds will compete with another maize strain unveiled last July by Swiss agribusiness Syngenta. Both companies used conventional breeding rather than genetic engineering to produce their seeds. new hybrids will increase maize yields by $5 \%$ in water-limited environments, such as the western states of the intensively agricultural Corn Belt region. That compares with the $15 \%$ yield gain promised by Syngenta for its maize. Both companies, as well as seed firm Monsanto, based in St Louis, Missouri, are also working on transgenic maize varieties, hoping to tap into a multibillion-dollar market (see Nature 466, 548-551; 2010).
Pioneer says that field studies show its
In theory, drought-tolerant varieties could fill the gap left in maize supplies in recent years as stocks have been diverted for ethanol production. But not everybody is convinced that these crops will make a big difference. "It's good news, but it's not great news," says David Zilberman, an agricultural economist at the University of California, Berkeley. No crop will survive a severe drought, he says, and other factors such as nutrient availability and soil quality are at play during water shortages, which tend to be more frequent but less severe than droughts. "It will be useful for a small number of really important areas," Zilberman says, "but my feeling is that people expect altogether too much from drought tolerance."

Creating drought-tolerant plants has proved to be a difficult challenge for plant breeders. Whereas resistance to a particular herbicide might be pinned down to one gene, the response to drought plays out across the genome. A plant's resilience also depends on when drought strikes - early or late in the life cycle, for instance - and on which nutrients
ONATURE.COM For Nature's recent food special, see: nature.com/food are available. Moreover, varieties that perform better when thirsty often underperform when water is plentiful. The industry researchers identified thousands of genes associated with drought tolerance, then incorporated them into their hybrids through conventional breeding. "All of this technology has just come together beautifully in the past ten years," says Jeff Schussler, senior research manager at Pioneer.

The new varieties will be marketed only in the United States, but efforts to develop drought-tolerant maize are also under way in Africa and Asia. Working with the Bill \& Melinda Gates Foundation and other donors, international agricultural research centres have already introduced dozens of conventional drought-tolerant varieties into 13 of the most important maize-producing countries in subSaharan Africa. These new varieties now make up $15-25 \%$ of the 19 million hectares of maize planted in these countries each year, according to Marianne Bänziger, deputy director-general for research and partnerships at the International Maize and Wheat Improvement Center (CIMMYT) in Mexico City. A recent study by CIMMYT and its partners suggests that the new varieties could increase yields by $10-34 \%$.

The big seed companies are also contributing expertise. Last year, South Africa was home to the first field trial for a transgenic droughttolerant maize crop, incorporating a gene from the variety currently under development by Monsanto. Meanwhile, CIMMYT recently partnered with the Syngenta Foundation for Sustainable Agriculture, based in Basel, Switzerland, to expand its drought-tolerant maize programme. "Within five years, we hope to have crops in Asia," Bänziger says. - 